\title{
ДИСКУССИОННЫЕ ВОПРОСЫ СОБЛЮДЕНИЯ КОНСТИТУЦИИ РОССИЙСКОЙ ФЕДЕРАЦИИ В ПРАВОПРИМЕНИТЕЛЬНОЙ И СУДЕБНОЙ ПРАКТИКЕ ПО ДЕЛАМ О ЗАЩИТЕ КОНКУРЕНЦИИ
}

Аннотация: Предметом исследования является сложсишаяся правоприменительная и судебная практика по делам о зашите конкуренции, в ходе которой органы государственной власти при осуществлении своих властных полномочий не в полной мере соблюдают нормы действующего законодательства в части соблюдения различных процедур установления доминирующего положения хозяйствующего субъекта на рынке. Указанная практика, вопреки требованиям о неукоснительном соблюдении принципа законности в деятельности органов публичной власти "затверждается" и судебной практикой, что не способствует установлению конституционно-правовых начал в экономической сфере. Методология исследования основана на применении иелого ряда общенаучных методов познания: анализ, сравнение, сопоставление и др. Основныл итогом настоящего исследования является попытка обратить внимание на случаи несоблюдения в современной правоприменительной и судебной практики органами государственной власти и судами положений части $2 \mathrm{~cm}$. 15 Конституции РФ, которые в свою очередь, составляют конституциионые гарантии защуиты экономических прав граждан и хозяйствуюших субъектов от неисполнение органами государственной власти Конституции РФ и иных нормативных актов. Практика "игнорирования" положений действующего законодательства при осуществлении органами публичной власти своих полномочий способствует непризнанию верховенства Конституции Российской Федерации и, по существу, означает игнорирование органами государственной власти положений действующего в РФ законодательства. Ключевые слова: Конституцчия РФ, защчита конкуренции, доминирующее положение, экономические права, судебная практика, законодательство РФ, Конституционный суд РФ, арбитражный суд, антимонопольный орган, административный регламент.

Abstract: The subject of this research is the current law enforcement and judicial practice in antimonopoly cases, in the process of which the government authorities do not fully adhere to the norms of the legislation with regards to upholding various procedures for establishing a dominant businesses position on the market. Despite the requirements on mandatory adherence to the principle of lawfulness in the work of the branches of public authority, the said practice is also being "strengthened" by the legal precedent, which does not contribute to establishing constitutional legal foundation within the economic sphere. The main result of this research is the attempt to shed light on the cases of non-compliance by courts and authorities with the part 2 of Article 15 of the Russian Constitution, which in turn represent the constitutional guarantees of protection of economic rights of the citizens and businesses from non-adherence by the branches of government with the constitution of the Russian Federation and other normative acts. The practice of "ignoring" the positions of this legislation in the work of public authority contributes to rejection of the supremacy of the Constitution of the Russian Federation. Keywords: Constitutional court of the Russian Federation, legislation of the Russian Federation, legal precedent, economic rights, dominant position, protection of competition, Constitution of the Russian Federation, court of arbitration, antimonopoly authority, administrative regulations.

огласно Конституции Российской Федерации в Российской Федерации гарантируются единство экономического пространства, свободное перемещение товаров, услуг, финансовых средств, поддержка конкуренции, свобода экономической деятельности, а также государственная защита прав и свобод человека и гражданина (статья 8, часть 1; статья 45, часть 1) и, кроме того, не допускается экономическая деятельность, направленная на монополизацию и недобросовестную конкуренцию (статья 34, часть 2).
Как отметил Конституционный Суд Российской Федерации в своем Постановлении от 18 июля 2008 года № 10-П, государство вправе и обязано осуществлять в сфере экономических отношений контрольную функцию, которая по своей конституционно-правовой природе производна от его организующего и регулирующего воздействия на общественные отношения и присуща всем органам государственной власти в пределах закрепленной за ними компетенции. Для проведения государ- 
DOI: $10.7256 / 1811-9018.2015 .7 .15781$

При цитировании этой статьи сноска на ооі обязательна

\section{Право и политика 7 (187) $\bullet 2015$}

ственной политики по содействию развитию товарных рынков и конкуренции, предупреждению, ограничению и пресечению монополистической деятельности и недобросовестной конкуренции федеральным законодателем в целях защиты прав и свобод граждан, занимающихся предпринимательской деятельностью (хозяйствующих субъектов), приняты соответствующие федеральные законы.

К таким федеральным законам относится, прежде всего, Федеральный закон «О защите конкуренции», который, определяет организационные и правовые основы защиты конкуренции, в том числе предупреждения и пресечения монополистической деятельности и недобросовестной конкуренции, а также недопущения, ограничения, устранения конкуренции федеральными органами исполнительной власти, органами государственной власти субъектов Российской Федерации, органами местного самоуправления, иными осуществляющими функции указанных органов органами или организациями, а также государственными внебюджетными фондами, Центральным банком Российской Федерации.

Ради достижения вышеуказанных целей, названный федеральный закон позволяет уполномоченному федеральному органу исполнительной власти - Федеральной антимонопольной службе России давать квалификацию действиям хозяйствующих субъектов, решениям органов власти на предмет их соответствия положениям Конституции РФ и иных нормативных актов, обеспечивающих единство экономического пространства, свободное перемещение товаров, свободу экономической деятельности в Российской Федерации, защиту конкуренции. Однако такая юридическая оценка тех или иных действий не может осуществляться произвольно, а должна происходит в строгом соответствии с нормами как материального, так и процессуального права в системе конкурентного законодательства.

Вместе с тем, практика деятельности антимонопольных органов и судебная практика арбитражных судов и «обновленного» Верховного суда РФ свидетельствует о том, что соблюдение норм, регламентирующих порядок юридической оценки действий (решений) субъектов рынка соблюдается не всегда, «грешит» этим и судебная практика. В качестве примера, автору хотелось бы рассмотреть практику антимонопольных органов и судов по применению положений ст. 39.1 Федерального закона от 26.07.2006 № 135-Ф3 «О защите конкуренции».
В соответствии с п.1 ст. 39.1 Федерального закона от 26.07.2006 № 135-Ф3 (ред. от 28.12.2013) «О защите конкуренции» в целях пресечения действий (бездействия), которые приводят или могут привести к недопущению, ограничению, устранению конкуренции, антимонопольный орган выдает хозяйствующему субъекту, занимающему доминирующее положение, предупреждение в письменной форме о прекращении действий (бездействия), которые содержат признаки нарушения антимонопольного законодательства, об устранении причин и условий, способствовавших возникновению такого нарушения, и о принятии мер по устранению последствий такого нарушения (далее - предупреждение). Таким образом, предупреждение как акт реагирования уполномоченного государственного органа - Федеральной антимонопольной службе РФ выдается исключительно субъектам, занимающим доминирующее положение на рынке. Указанное обстоятельство подтверждается и Приказом ФАС РФ от 14.12.2011 № 874 «Об утверждении Порядка выдачи предупреждения о прекращении действий (бездействия), которые содержат признаки нарушения антимонопольного законодательства». В соответствии с п.1.3 вышеуказанного Порядка выдачи предупреждения о прекращении действий (бездействия), которые содержат признаки нарушения антимонопольного законодательства, антимонопольный орган признает положение хозяйствующего субъекта доминирующим на рынке определенного товара в соответствии со статьей 5 Федерального закона от 26.07.2006 № 135-Ф3 «О защите конкуренции», Приказом ФАС России от 25.05.2012 № 345 «Об утверждении административного регламента Федеральной антимонопольной службы по исполнению государственной функции по установлению доминирующего положения хозяйствующего субъекта при рассмотрении заявлений, материалов, дел о нарушении антимонопольного законодательства и при осуществлении государственного контроля за экономической концентрацией» и Порядком проведения анализа состояния конкуренции на товарном рынке, утвержденным приказом ФАС России от 28.04.2010 № 220 (зарегистрирован Минюстом России 02.08.2010 № 18026).

Вместе с тем, в деле А40-90629/13 Арбитражный суд города Москвы рассматривая заявление Екатеринбургского муниципального унитарного предприятия «Трамвайно-троллейбусное управление» к ФАС России о признании незаконным предупреждения от 29.04.2013 № ИА/17397/13 указал, 
что «по результатам проведения анализа рынка, на основании аналитического отчета составленного по его результатам в порядке, установленном Приказом ФАС России от 28.04.2010г. № 220 «Об утверждении порядка проведения анализа состояния конкуренции на товарном рынке», было установлено, что совокупная доля ЕМУП «ТТУ» и ЕМУП «Горсвет» на рынке услуг по предоставлению опор линий контактной сети, опор освещения и опор линий электропередач для размещения операторами связи кабелей ВОЛС в г. Екатеринбурге в 2011-2012 гг. более $50 \%$ и составляет 99,0 \% в 2011 г. и 96,88 \% в 2012 г., на основании чего положения данных организаций на рынке признается доминирующим».

Таким образом, судебной практикой допускается признание доминирующего положения хозяйствующего субъекта на соответствующем рынке лишь по результатам проводимого антимонопольным органов анализа рынка в соответствии с Порядком проведения анализа состояния конкуренции на товарном рынке, утвержденным приказом ФАС России от 28.04.2010 № 220 (зарегистрирован Минюстом России 02.08.2010 № 18026).

Вместе с тем, в соответствии с действующим законодательством государственная функция по установлению доминирующего положения хозяйствующего субъекта при рассмотрении заявлений, материалов, дел о нарушении антимонопольного законодательства и при осуществлении государственного контроля за экономической концентрацией должна осуществляться антимонопольными органами в соответствии с Приказом ФАС России № 345 от 25 мая 2012 года «Об утверждении административного регламента ФАС по исполнению государственной функции по установлению доминирующего положения хозяйствующего субъекта при рассмотрении заявлений, материалов, дел о нарушении антимонопольного законодательства и при осуществлении государственного контроля за экономической концентрацией» (далее по тексту - Регламент).

В соответствии с п. 3.10 вышеуказанного Регламента анализ состояния конкуренции проводится исполнителем ответственного структурного подразделения.

По результатам проведения анализа состояния конкуренции на товарном рынке составляется аналитический отчет, в котором приводятся результаты проведенного анализа, а также содержится заключение о наличии признаков доминирующего положения хозяйствующего субъекта (далее - аналитический отчет).
В соответствии с п. 3.12. в случае обнаружения признаков наличия доминирующего положения, а также нарушения статьи 10 Закона о защите конкуренции ответственное структурное подразделение осуществляет подготовку докладной записки, которая подлежит внутриведомственной правовой экспертизе. При получении заключения о наличии признаков нарушения антимонопольного законодательства, подготовленного по результатам внутриведомственной правовой экспертизы (далее - заключение), исполнитель осуществляет подготовку проекта приказа антимонопольного органа о возбуждении дела и создании комиссии по рассмотрению дела о нарушении антимонопольного законодательства. Указанный проект приказа с приложением докладной записки, заключения, документов и материалов, свидетельствующих о фактах нарушения антимонопольного законодательства, а также аналитического отчета направляется руководителю антимонопольного органа.

П. 3.13 Регламента устанавливает, что руководитель антимонопольного органа в течение пяти рабочих дней после получения документов, указанных в пункте 3.12 Регламента, вправе принять одно из следующих решений:

- о возбуждении дела о нарушении антимонопольного законодательства и о создании комиссии, которое оформляется приказом антимонопольного органа;

- об отказе в возбуждении дела о нарушении антимонопольного законодательства в связи с отсутствием признаков его нарушения, которое оформляется письмом на имя Заявителя;

- о возвращении документов в ответственное структурное подразделение на доработку (оформляется резолюцией, содержащей соответствующее поручение).

При этом, согласно п. 3.15 Регламента доминирующее положение хозяйствующего субъекта считается установленным в случае принятия руководителем антимонопольного органа решения о возбуждении по признакам нарушения статьи 10 Закона о защите конкуренции дела о нарушении антимонопольного законодательства и о создании комиссии по рассмотрению дела о нарушении антимонопольного законодательства.

При этом, вышеназванный Регламент обязывает антимонопольный орган направлять в течении трех дней со дня издания копию приказа о возбуждении дела и создании комиссии по рассмотрению дела 
DOI: $10.7256 / 1811-9018.2015 .7 .15781$

При цитировании этой статьи сноска на ооі обязательна

\section{Право и политика 7 (187) • 2015}

о нарушении антимонопольного законодательства заявителю и ответчику по делу, тем самым, соблюдается принцип информационной открытости при принятии органом государственной власти решений, которые ограничивают экономическую деятельность хозяйствующего субъекта, с другой стороны позволяют обжаловать заинтересованными лицами упоминаемое решение антимонопольного органа о возбуждении дела и создании комиссии по рассмотрению дела.

Вместе с тем, как уже упоминалось ранее, судами всех инстанций, в том числе и Верховным судом РФ в деле А40-90629/13 факт несоблюдения антимонопольным органом установленной действующим законодательством процедуры установления доминирующего положения хозяйствующего субъекта не нашел своей должной оценки и не был воспринят как препятствие для вынесения в порядке ст.39.1 Федерального закона от 26.07.2006 № 135-Ф3 «О защите конкуренции» в адрес ЕМУП «Трамвайнотроллейбусное управление» предупреждения.

Ситуация с соблюдением норм, устанавливающих порядок установления доминирующего положения хозяйствующего субъекта на определенном рынке усугубляется негативным способом и разъяснениями Постановления Пленума ВАС РФ от 30.06.2008 № 30 «О некоторых вопросах, возникающих в связи с применением арбитражными судами антимонопольного законодательства», пунктом 13 которого определено, что установление доминирующего положения хозяйствующего субъекта производится с учетом его доли на рынке определенного товара, при этом при рассмотрении споров о нарушениях, совершенных лицом, не включенным в реестр хозяйствующих субъектов, не может быть отказано в признании его занимающим доминирующее положение на рынке лишь в связи с тем, что такое лицо в данный реестр не включено.

В соответствии с п.1 и 2 статьи 15 Конституции РФ - Конституция Российской Федерации имеет высшую юридическую силу, прямое действие и применяется на всей территории Российской Федерации. Органы государственной власти, органы местного самоуправления, должностные лица, граждане и их объединения обязаны соблюдать Конституцию Российской Федерации и законы.

Во исполнение вышеуказанных конституционных положений, на основании подп. а п. 8 ч. 1 ст. 23 Федерального закона от 26.07.2006 № 135-Ф3 «О защите конкуренции» на антимонопольный орган возложена обязанность ведения реестра хозяйствующих субъектов (за исключением финансовых организаций), имеющих долю на рынке определенного товара в размере более чем тридцать пять процентов или занимающих доминирующее положение на рынке определенного товара, если в отношении такого рынка другими федеральными законами в целях их применения установлены случаи признания доминирующим положения хозяйствующих субъектов (далее - реестр).

Порядок формирования и ведения реестра установлен Постановлением Правительства от 19.12.2007 № 896 «Об утверждении Правил формирования и ведения Реестра хозяйствующих субъектов, имеющих долю на рынке определенного товара в размере более чем 35 процентов или занимающих доминирующее положение на рынке определенного товара, если в отношении такого рынка федеральными законами установлены случаи признания доминирующим положения хозяйствующих субъектов» (далее - Правила).

Согласно п. 13 Правил основаниями для принятия решения о включении сведений о хозяйствующем субъекте в реестр являются: а) аналитический отчет, подготовленный: в рамках рассмотрения дела о нарушении антимонопольного законодательства; при рассмотрении ходатайства о даче согласия на осуществление сделок и иных действий или уведомления о сделках и иных действиях, подлежащих государственному контролю за экономической концентрацией; по итогам рассмотрения заявления хозяйствующего субъекта; по итогам анализа состояния конкуренции на товарном рынке, проведенного антимонопольным органом по собственной инициативе; б) решение суда о включении сведений о хозяйствующем субъекте в реестр.

В силу п. 16 Правил решения о включении сведений о хозяйствующем субъекте в реестр оформляются приказом антимонопольного органа. Копии приказа антимонопольного органа направляются хозяйствующему субъекту и в Федеральную службу государственной статистики в срок, не превышающий 3 рабочих дней с даты принятия соответствующего решения.

В соответствии с пунктом 17 Правил решения антимонопольного органа о включении сведений о хозяйствующем субъекте в реестр, исключении соответствующих сведений из реестра, внесении изменений в содержащиеся в реестре сведения могут быть обжалованы в порядке, установленном 
законодательством Российской Федерации. (абз. 5 п. 13 названного Постановления).

Приказом ФАС РФ от 17.01.2007 № 6 утвержден регламент Федеральной антимонопольной службы по исполнению государственной функции по ведению реестра хозяйствующих субъектов, имеющих долю на рынке определенного товара более чем тридцать пять процентов (далее - Регламент). В соответствии с п. 1.2. указанного Регламента, исполнение государственной функции по ведению реестра хозяйствующих субъектов, имеющих долю на рынке определенного товара более чем тридцать пять процентов осуществляется в соответствии с Конституцией Российской Федерации от 12 декабря 1993 года; федеральным законом от 26 июля 2006 года № 135-Ф3 «О защите конкуренции» и др. нормативными актами.

Статья 68 арбитражного процессуального кодекса РФ четко устанавливает, что обстоятельства дела, которые согласно закону должны быть подтверждены определенными доказательствами, не могут подтверждаться в арбитражном суде иными доказательствами.

Таким образом, исключение п.13 Постановления Пленума ВАС РФ от 30.06.2008 № 30 «О некоторых вопросах, возникающих в связи с применением арбитражными судами антимонопольного законодательства», из числа доказательств установления доминирующего положения хозяйствующего субъекта факта исполнения антимонопольным органом государственной функции о включении указанного субъекта рынка в реестр хозяйствующих субъектов фактически направлено на предоставление антимоно- польному органу права не исполнять предписания действующего законодательства Российской Федерации, что безусловно не согласуется с принципом равенства всех перед законом и судом (п. 1 ст. 19 Конституции Российской Федерации), а также противоречит закрепленной пунктом 2 статьи 15 Конституции Российской Федерации обязанности соблюдать Конституцию Российской Федерации и законы.

В соответствии со статьей 19 (части 1 и 2) Конституции Российской Федерации все равны перед законом и судом; государство гарантирует равенство прав и свобод человека и гражданина независимо от пола, расы, национальности, языка, происхождения, имущественного и должностного положения, места жительства, отношения к религии, убеждений, принадлежности к общественным объединениям, а также других обстоятельств. Указанные положения, в совокупности с нормами части 2 ст. 15 Конституции РФ составляют конституционные гарантии защиты экономических прав граждан и хозяйствующих субъектов от неисполнение органами государственной власти Конституции РФ и иных нормативных актов и не возлагает на соответствующие органы судебной власти права в своих судебных актах «освобождать» органы власти от точного и единообразного исполнения положений нормативных актов, поскольку указанная практика способствует непризнанию верховенства Конституции Российской Федерации и, по существу, означает игнорирование уполномоченными органами государственной власти при осуществлении принадлежащих ему властных полномочий положений действующего в РФ законодательства.

\section{Библиография:}

1. Федеральный закон от 26.07.2006 N 135-Ф3 «О защите конкуренции»/Российская газета, N 162, 27.07.2006

2. Приказ ФАС России от 25.05.2012 N 345 «Об утверждении административного регламента Федеральной антимонопольной службы по исполнению государственной функции по установлению доминирующего положения хозяйствующего субъекта при рассмотрении заявлений, материалов, дел о нарушении антимонопольного законодательства и при осуществлении государственного контроля за экономической концентрацией»//Бюллетень нормативных актов федеральных органов исполнительной власти, N 8 25.02.2013

3. Приказ ФАС России от 28.04.2010 N 220 «Об утверждении Порядка проведения анализа состояния конкуренции на товарном рынке»//Бюллетень нормативных актов федеральных органов исполнительной власти, № 34, 23.08.2010.

4. Постановление Конституционного Суда РФ от 18.07.2008 № 10-П «По делу о проверке конституционности положений абзаца четырнадцатого статьи 3 и пункта 3 статьи 10 Федерального закона «О защите прав юридических лиц и индивидуальных предпринимателей при проведении государственного контроля (надзора)» в связи с жалобой гражданина В.В. Михайлова»/ Российская газета, № 163, 01.08.2008,

5. Постановление Пленума ВАС РФ от 30.06.2008 № 30 «О некоторых вопросах, возникающих в связи с применением арбитражными судами антимонопольного законодательства» // Вестник ВАС РФ, № 8, август, 2008

6. Кожевников О.А. Совершенствование судебной практики по вопросам обращения с отходами производства и потребления как одна из задач «обновленного» Верховного суда РФ // Административное и муниципальное право. - 2014. - 9. - C. 975 - 980. DOI: 10.7256/1999-2807.2014.9.12711. 
DOI: $10.7256 / 1811-9018.2015 .7 .15781$

При цитировании этой статьи сноска на dоі обязательна

\section{Право и политика 7 (187) • 2015}

7. Исполинов А.С. Поиск баланса между свободами внутреннего рынка и правами человека в судебной практике ЕС // Журнал зарубежного законодательства и сравнительного правоведения / Journal of foreighn legislation and comparative law. - 2012. -6. - C. $38-49$.

\section{References (transliterated):}

1. Kozhevnikov O.A. Sovershenstvovanie sudebnoi praktiki po voprosam obrashcheniya s otkhodami proizvodstva i potrebleniya kak odna iz zadach «obnovlennogo» Verkhovnogo suda RF // Administrativnoe i munitsipal'noe pravo. - 2014. - 9. - C. 975 980. DOI: 10.7256/1999-2807.2014.9.12711.

2. Ispolinov A.S. Poisk balansa mezhdu svobodami vnutrennego rynka i pravami cheloveka v sudebnoi praktike ES // Zhurnal zarubezhnogo zakonodatel'stva i sravnitel'nogo pravovedeniya / Journal of foreighn legislation and comparative law. - 2012. 6. - C. $38-49$. 